УДК 622.232

DOI: $\underline{\text { https://doi.org/10.36910/6775-2313-5352-2019-14-23 }}$

Стасюк В.M.

Луцький національний технічний університет

\title{
МАТЕМАТИЧНА МОДЕЛЬ ПОЧАТКОВОГО ЕТАПУ ФАЗИ ФОРМУВАННЯ РУШІЙНОГО ІМПУЛЬСУ ПНЕВМОПРИВОДА З МЕХАНІЧНИМ ЗВ'ЯЗКОМ МІЖ ПОРШНЕМ-УДАРНИКОМ ТА СИСТЕМОЮ КЕРУВАННЯ
}

Пневмоприводи характеризуються вищою надійністю порівняно з іншими типами приводів під час експлуатаиії в несприятливих умовах. Однак стиснене повітря є досить дорогим енергоносієм. Тому завдання здешевлення експлуатаиії пневматичних машин набуло на сьогодні особливої актуальності. Ефективним шляхом його вирішення є трунтований аналіз робочих циклів приводів з метою виявлення фаз, енергоємність яких найвища, та пошук конструктивних рішень щодо ї̈ зменшення.

Об'єктом дослідження служить пневмопривод ударних машин із механічним зв'язком між поринем-ударником та системою керування. У роботі досліджено фазу наповнення камери робочого ходу цьього привода як таку, щчо чинить визначальний вплив на формування енергетичних характеристик ударної машини $i$ безпосередньо пов'язана із витратами стисненого повітря. Фазу розглянуто розподіленою на початковий та завершальний етапи, на яких здійснюється формування рушійного імпульсу для виникнення руху поршня-ударника.

Виконано детальний аналіз початкового етапу, розроблено його математичну модель, яку варто використовувати при проектуванні енергоощадних конструкиій пневматичних приводів розглядуваного типу. Ї̈̈ використання дозволить полегшити виконання завдання щзодо отримання заданих енергетичних характеристик $і$ швидкодї ударної машини та вибору потрібних для цього рачіональних величин конструктивних параметрів привода при оптимальних витратах стисненого повітря.

Ключові слова: пневмопривод, поршень-ударник, фаза, початковий етап, математична модель.

Постановка проблеми у загальному вигляді та їі зв'язок із важливими науковими чи практичними завданнями. Пневматичні приводи відомі в науці та техніці як найбільш надійні серед інших видів приводів під час експлуатації машин та механізмів на їх основі в умовах несприятливих або агресивних середовищ. Зокрема, це стосується пневматичних машин 3 приводами, виконавчі органи яких здійснюють вібраційний або ударний вплив на відповідний об'єкт. Однак собівартість стисненого повітря досить висока. Тому на сьогоднішній день актуалізувалося завдання проведення якомога глибших досліджень пневматичних приводів, спрямованих на зменшення їх енергоспоживання. Щодо пневмоприводів ударних машин, то для досягнення цього завдання доцільно виконувати детальний аналіз їх робочих циклів, виокремлювати та досліджувати ті фази, які істотно впливають на витрати стисненого повітря, за можливості регулювати ї протікання шляхом оптимізації розмірів конструктивних параметрів пневмоциліндра, поршня-ударника, інших складових привода, однак забезпечуючи при цьому отримання заданих енергетичних показників ударної машини та потрібну іiі швидкодію. Зокрема, це стосується також пневматичних приводів із механічним зв'язком між поршнем-ударником та системою керування, фази наповнення якого досить енергоємні.

Аналіз останніх досліджень і публікацій, в яких започатковано розв'язання даної проблеми. Глибоким дослідженням пневматичних приводів присвячені роботи $[1 ; 2]$ та інші. Однак в них, як і в наукових публікаціях вітчизняних та зарубіжних науковців, результатів фазних досліджень робочих циклів пневмоприводів із механічним зв'язком між поршнемударником і системою керування, присвячених зменшенню споживання стисненого повітря, не виявлено.

Постановка завдання: дослідити початковий етап фази формування рушійного імпульсу пневмопривода із механічним зв'язком між поршнем-ударником та системою керування як такий, що чинить визначальний вплив на формування енергетичних характеристик ударної машини (сили та енергії удару) та іï швидкодію і безпосередньо пов'язаний із витратами енергоносія - стисненого повітря шляхом складання математичної моделі, яку можна буде використовувати при створенні нових конструкцій пневматичних приводів із таким самим чи 
подібним принципом дії, зорієнтованих на оптимізацію чи мінімізацію витрат стисненого повітря.

У приводах 3 механічним зв'язком між поршнем-ударником та системою керування фазами, які безпосередньо впливають на витрату стисненого магістрального повітря, $\epsilon$, насамперед, фази наповнення робочих камер, тобто фази початку та кінця робочого циклу. Початковий рушійний (силовий) імпульс, від якого залежать енергетичні показники ударної машини (сила та енергія удару), формується саме під час впуску стисненого повітря 3 магістралі в камеру робочого ходу (рис. 1). Причому фазу формування рушійного імпульсу доцільно розглядати у вигляді двох етапів - початкового та завершального. Початковий етап фази формування рушійного імпульсу триває 3 моменту відкриття поршнем-ударником впускних елементів камери робочого ходу Б (під час здійснення ним холостого ходу) до його повної зупинки в крайній «мертвій» точці цієї камери. Тобто в «замкненій» камері Б протягом всього цього етапу повітря стискується, чим він відрізняється від другого (завершального) етапу фази формування рушійного імпульсу. При цьому поршень-ударник до моменту повної зупинки рухався за рахунок, по-перше, розширення стисненого повітря в камері холостого ходу $\mathrm{A}$, яке надходило через відкритий впускний клапан цієї камери на фазі нанесення удару по хвостовику робочого інструмента, $i$, по-друге, за рахунок імпульсного силового впливу самого хвостовика на цій фазі після нанесення по ньому удару.

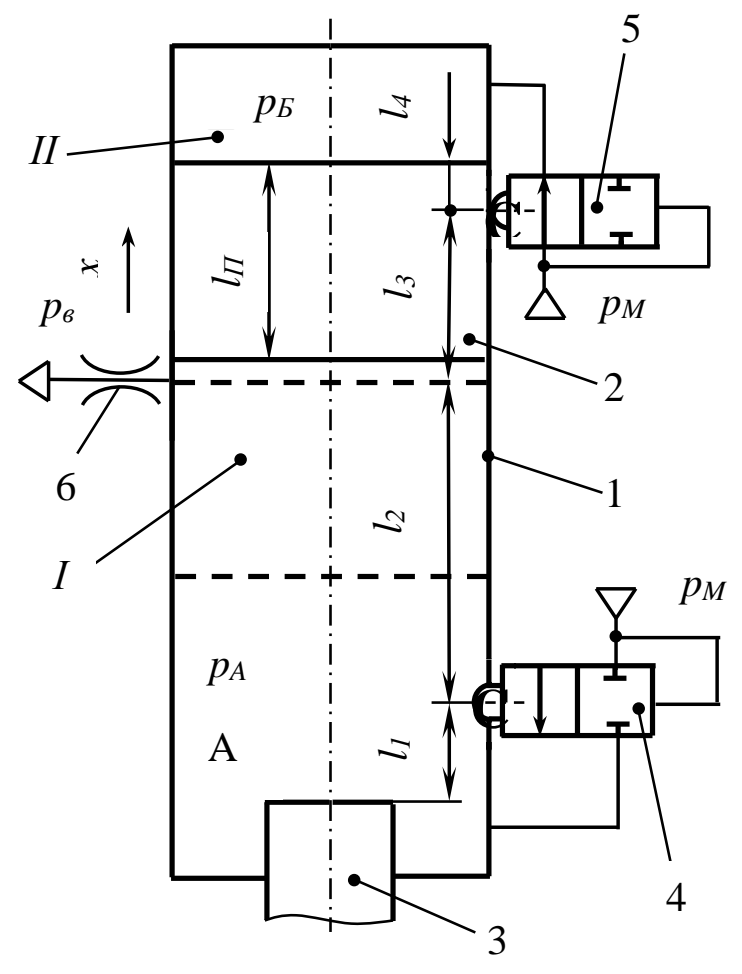

Рис. 1. Розрахункова схема пневматичного привода з механічним зв'язком між поршнемударником та системою керування його рухом для початкового етапу фази формування рушійного імпульсу:

1 - пневмоциліндр; 2 - поршень-ударник; 3 - хвостовик робочого інструмента; 4 впускний клапан камери холостого ходу; 5 - впускний клапан камери робочого ходу; 6 випускні отвори; А - камера холостого ходу; Б - камера робочого ходу; $I$ - одне із проміжних положень поршня-ударника під час його руху (а саме момент перекриття ним випускних отворів 6); II - кінцеве положення поршня-ударника в камері робочого ходу Б під час

здійснення ним холостого ходу; $x$ - напрямок руху поршня-ударника (холостий хід)

Завершальний етап фази формування рушійного імпульсу триває з моменту початку руху поршня-ударника 3 крайньої «мертвої» точки камери робочого ходу Б до моменту закриття впускних клапанів цієї камери. В межах даної публікації розглянемо тільки початковий етап фази формування рушійного імпульсу у вищезазначеній камері, тобто завершення руху поршня-ударника під час здійснення ним холостого ходу. 
Протягом початкового етапу фази формування рушійного імпульсу в камері робочого ходу Б в неї надходить стиснене повітря 3 магістралі, а 3 камери холостого ходу А відпрацьоване повітря в цей час виходить в атмосферу. Динаміка цього етапу фази досить складна, оскільки залежить від багатьох параметрів, зокрема, від таких лінійних розмірів пневмоциліндра, як відстань між вісями випускних отворів пневмоциліндра та впускного клапана камери робочого ходу Б, компенсаційного об'єму та кільцевої щілини впускного елемента цієї камери, діаметрів випускних отворів у пневмоциліндрі, довжини поршняударника тощо.

Тому доцільно скласти математичну модель, дослідження якої дозволить визначати оптимальні величини лінійних та діаметральних розмірів пневматичного привода для забезпечення отримання потрібних енергетичних характеристик ударного вузла (сили та анергії удару) при належній швидкодії. Для цього потрібно прийняти ряд наступних припущень:

- тиск і температура стисненого повітря в магістралі $\epsilon$ постійними величинами, при цьому температура відповідає температурі навколишнього середовища;

- тиск стисненого повітря в магістралі 0,5 МПа, що дозволяє розглядати його як ідеальний газ із властивими для нього фізичними характеристиками;

- враховуючи високі швидкісні характеристики ударного вузла i, відповідно, незначну тривалість термодинамічних процесів у камерах робочого та холостого ходу привода, його теплообміном 3 навколишнім середовищем можна знехтувати, а фізичні процеси в робочих камерах прийняти адіабатними;

- маса клапанів впускних елементів, час їх відкривання та закривання, а також тривалість удару незначні (на порядок менші за тривалість робочого циклу привода), тому ними можна знехтувати; відкриття та закриття клапанів відбувається релейно, при цьому клапани миттєво піднімаються на максимальну висоту;

- втрати повітря внаслідок його просочування з камери стиснення у камеру розрідження під час робочого або холостого ходу поршня-ударника незначні й ними можна знехтувати;

- випускні отвори миттєво відкриваються та закриваються поршнем-ударником на всю величину.

Для таких умов зникає необхідність складання та розв'язування рівнянь термодинаміки, а процес дослідження динаміки початкового етапу фази формування рушійного імпульсу обмежується аналізом складених рівнянь руху поршня-ударника і залежностей, які описують зміну тиску в робочих камерах пневматичного привода.

Шляхом дослідження специфіки фізичних процесів у робочих камерах привода та руху поршня-ударника на окремих фазах робочого циклу, обумовлених конструктивними параметрами пневмопривода (а саме складанням та аналізом їх математичних моделей), виконання відповідних перетворень та спрощень, а також використання результатів наукових досліджень, виконаних у роботі [3], отримано математичну модель початкового етапу фази формування рушійного імпульсу пневматичного привода 3 механічним зв'язком між поршнемударником та системою керування його рухом:

$$
\left\{\begin{array}{l}
m \frac{d^{2} x}{d t^{2}}=\left(p_{A}-p_{B}\right) F-\left[\pi D \frac{d x}{d t}\left(\frac{K_{D} p_{M} D}{4}+l_{\Pi} \frac{v}{\Delta}\right)+m g\right] \\
p_{A}=\frac{0,47 p_{M}\left[1+\left(1+\frac{l_{4}}{\psi_{V A} S+l_{1}+l_{2}+l_{3}}\right)^{-k}\right]}{\left(1+\frac{l_{2}}{\psi_{V A} S+l_{1}}\right)^{k} \cdot\left(1+\frac{l_{3}}{\psi_{V A} S+l_{1}+l_{2}}\right)^{k}} p_{a} ; \\
p_{Б}=0,5 p_{a}\left(1-\frac{l_{3}}{S\left(1+\psi_{V D}\right)-\left(l_{1}+l_{2}\right)}\right)^{-k}+0,8 p_{M},
\end{array}\right.
$$

де $m$ - маса поршня-ударника;

$p_{A}, p_{\bar{B}}$ - тиск повітря відповідно в камері холостого ходу А та в камері робочого ходу Б пневматичного приводу; 
$F, \quad D, \quad l_{\Pi}-$ відповідно площа поперечного перерізу, діаметр та довжина суцільноциліндричного поршня-ударника;

$K_{D}-$ коефіцієнт, який враховується при визначенні сили сухого тертя; залежить від величини діаметра поршня-ударника;

$p_{M}$ - абсолютний тиск стисненого повітря в магістралі, від якої здійснюється живлення ударного вузла;

$v$ - середня величина коефіцієнта кінематичної в'язкості;

$\Delta-$ зазор між суцільноциліндричним тілом поршня-ударника та «дзеркалом» пневматичного циліндра;

$g$ - прискорення вільного падіння;

$l_{1}$ - відстань від торця ударного інструмента виконавчого вузла до вісі впускного клапана камери холостого ходу;

$l_{2}$ - відстань, яку проходить поршень-ударник після закриття впускного клапана камери холостого ходу до моменту перекриття ним випускних отворів. Тобто це відстань між віссю впускного клапана камери холостого ходу і ударним торцем поршня-ударника в момент перекриття ним випускних отворів;

$l_{3}$ - відстань між випускними отворами пневмоциліндра та віссю впускного клапана камери робочого ходу;

$l_{4}$ - відстань, яку проходить поршень-ударник в камері робочого ходу після вмикання iï впускного клапана під час першого етапу фази формування рушійного імпульсу;

$\psi_{V A}-$ коефіцієнт, який характеризує співвідношення між довжиною компенсаційної камери холостого ходу та величиною ходу поршня-ударника;

$S$ - хід поршня-ударника;

$k$ - коефіцієнт адіабати;

$p_{a}$ - атмосферний тиск;

$\psi_{V Б}-$ коефіцієнт, який характеризує співвідношення між довжиною компенсаційної камери робочого ходу та величиною ходу поршня-ударника.

Отримані результати розрахунків за цією моделлю доцільно використовувати при подальшому визначенні енергетичних характеристик ударного вузла (машини) та його швидкодії, а також при виборі потрібних для цього оптимальних величин конструктивних параметрів привода.

Вагомим чинником при проектуванні пневматичних приводів ударних вузлів чи машин $\epsilon$ визначення тривалості як робочого циклу в цілому, так і тривалості кожної із його фаз. Інформація про час протікання кожної окремо взятої фази дозволяє знаходити резерви для скорочення тривалості (за необхідності) робочого циклу або оптимізувати іiі. У випадку необхідності зменшення часу протікання окремо взятої фази здійснюється варіювання розмірами відповідних конструктивних параметрів приводу, величиною тиску в мережі живлення тощо.

У результаті проведених досліджень встановлено, що тривалість початкового етапу фази формування рушійного імпульсу пневматичного привода з механічним зв'язком між поршнемударником та системою керування його рухом визначатиметься за формулою:

$$
\begin{aligned}
t=\left\{2 m l_{4} /[0,\right. & 9 p_{M} F-0,47 p_{M} F\left(1+\frac{l_{2}}{\psi_{V A} S+l_{1}}\right)^{-k} \times\left(1+\frac{l_{3}}{\psi_{V A} S+l_{1}+l_{2}}\right)^{-k} \times \\
& \left.\left.\times\left(1+\frac{l_{4}}{\psi_{V A} S+l_{1}+l_{2}+l_{3}}\right)^{-k}-0,5 p_{a} F\right]\right\}^{0,5} .
\end{aligned}
$$

Безумовно, енергетичні показники ударного вузла (які починають формуватись на початковому етапі фази формування рушійного імпульсу) в значній мірі залежать від витратних характеристик приводу. Від них залежать також величина ходу поршня-ударника, частота ударів тощо. Згідно рівняння Сен-Венана i Ванцеля [2], масова витрата стисненого 
магістрального повітря $G_{M Б}$ у камеру робочого ходу Б на початковому етапі фази формування рушійного імпульсу в цій камері для нашого випадку визначатиметься за формулою:

$$
G_{M B}=\frac{f_{5}^{e} p_{M} K \varphi\left(\sigma_{\bar{b}}\right)}{\sqrt{R T_{M}}},
$$

де $f_{5}^{e}$ - ефективна площа прохідного перерізу впускного елемента 5 камери робочого ходу Б: $f_{5}^{e}=\mu f_{5}^{\prime} \quad(\mu-$ коефіцієнт витрати для впускного елемента камери робочого ходу Б, визначається за виразом: $\mu=\sqrt{\frac{1+\sigma}{1+\sigma+4 \sigma(\xi-\ln \sigma)}}$, де $\sigma$ - відношення тиску в середовищі, в яке надходить газ, то тиску в середовищі, з якого він витікає; $\xi$ - коефіцієнт сумарних втрат повітря, визначається за формулою: $\xi=\frac{0,5 \lambda l}{d}$, де $\lambda$ - коефіцієнт тертя; $l$ і $d$ - відповідно довжина та діаметр конструктивного елемента, в якому визначаються втрати енергії потоку повітря; $f_{5}^{\prime}$ - фактична площа прохідного перерізу робочого вікна впускного елемента 5);

$K$ - коефіцієнт: $K=[2 k /(k-1)]^{0,5}$;

$\varphi\left(\sigma_{5}\right)$ - функція витрати для камери робочого ходу Б;

$R$ - газова стала;

$T_{M}$ - температура стисненого повітря в магістралі.

За рівняння Сен-Венана і Ванцеля [2], масова витрата повітря $G_{6 A} 3$ камери холостого ходу А на початковому етапі фази формування рушійного імпульсу в камері робочого ходу Б для нашого випадку визначатиметься за формулою:

$$
G_{6 A}=f_{6}^{e} p_{A} K \varphi\left(\sigma_{A}\right) /\left(R T_{M}\right)^{0,5},
$$

де $f_{6}^{e}$ - ефективна площа прохідного перерізу випускних отворів $6: f_{6}^{e}=\mu_{1} f_{6}^{\prime}$ (де $\mu_{1}-$ коефіцієнт витрати для випускних отворів; $f_{6}^{\prime}$ - фактична площа випускних отворів). Величини $\mu_{1}$ та $f_{6}^{\prime}$ визначаються аналогічно попередньому випадку для випадку наповнення камери робочого ходу Б стисненим магістральним повітрям;

$\varphi\left(\sigma_{A}\right)$ - функція витрати для камери холостого ходу А.

Витратні функції $\varphi\left(\sigma_{Б}\right)$ та $\varphi\left(\sigma_{A}\right)$ залежать від видів термодинамічних процесів, що протікають в робочих камерах пневмопривода [2]. Оскільки згідно прийнятих раніше припущень фізичні процеси у камерах робочого та холостого ходів привода прийнято адіабатними, то функції $\varphi\left(\sigma_{\bar{b}}\right)$ та $\varphi\left(\sigma_{A}\right)$ визначатимуться за формулами:

$$
\begin{aligned}
& \left.\begin{array}{l}
\varphi\left(\sigma_{A}\right)=\sqrt{\sigma_{A}^{2 / k}-\sigma_{A}^{(k+1) / k}} \\
\varphi\left(\sigma_{\bar{B}}\right)=\sqrt{\sigma_{B}^{2 / k}-\sigma_{B}^{(k+1) / k}}
\end{array}\right\} \text { при } 0,528<\sigma_{A}, \sigma_{\bar{B}}<1 \text {; } \\
& \varphi\left(\sigma_{A}\right)=0,2588 \\
& \text { при } 0<\sigma_{A}, \sigma_{B}<0,528 \text {. } \\
& \varphi\left(\sigma_{\bar{B}}\right)=0,2588
\end{aligned}
$$

Висновок. Запропоновану математичну модель доцільно використовувати при проектуванні енергоощадних конструкцій пневматичних приводів із механічним зв'язком між поршнем-ударником та системою керування. Вона дозволить істотно полегшити виконання завдання щодо отримання заданих енергетичних характеристик та швидкодії ударного вузла 
(машини) та вибору потрібних для цього оптимальних величин конструктивних параметрів привода при оптимальних витратах стисненого повітря.

Перспективи подальших досліджень у даному напрямку полягають у дослідженні завершального етапу фази формування рушійного імпульсу в камері робочого ходу, а також сил протидії здійсненню поршнем-ударником імпульсного навантаження на робочий орган 3 метою їх зменшення або оптимізації та задля економії енергоресурсів.

\section{Інформаційні джерела}

1. Герц Е.В., Крейнин Г.В. Расчет пневмоприводов. Справочное пособие. М.: Машиностроение, 1975. 272 с.

2. Федорець В.О., Педченко М.Н., Струтинський В.Б. та ін. Гідроприводи та гідропневмоавтоматика: підручник / за ред. В.О. Федорця. Київ: Вища шк., 1995. 463 с.

3. Стасюк В.М. Пневматичний привод виконавчих органів ударних машин із механічним зв'язком поршня-ударника 3 впускними елементами: дис...канд. техн. наук: 050203. Вінниця, 2003. $296 \mathrm{c}$.

Стасюк В.М.

Луцкий национальный технический университет

\section{МАТЕМАТИЧЕСКАЯ МОДЕЛЬ НАЧАЛЬНОГО ЭТАПА ФАЗЫ ФОРМИРОВАНИЯ ДВИЖУЩЕГО ИМПУЛЬСА ПНЕВМОПРИВОДА С МЕХАНИЧЕСКОЙ СВЯЗЬЮ МЕЖДУ ПОРШНЕМ-УДАРНИКОМ И СИСТЕМОЙ УПРАВЛЕНИЯ}

Пневмоприводы характеризуются повышенной надежностью в сравнении с другими типами приводов во время эксплуатации в неблагоприятных условиях. Однако сжатый воздух достаточно дорогой энергоноситель. Поэтому задача удешевления эксплуатации пневматических машин приобрела сегодня особую актуальность. Эффективным путем ее решения является глубокий анализ рабочих циклов приводов с целью выявления фаз, энергоемкость которых самая высокая, и поиск конструктивных решений по ее уменьшению.

Объектом исследования служит пневмопривод ударных машин с механической связью между поршнем-ударником и системой управления. В работе проведены исследования фазы наполнения камеры рабочего хода этого привода, которая оказывает определяющее влияние на формирование энергетических характеристик ударной машины и непосредственно связана с затратами сжатого воздуха. Фазу рассмотрено дифференцированной на начальный и заключительный этапы, на которых осуществляется формирование движущего импульса для возникновения движения поршня-ударника.

Выполнен детальный анализ начального этапа, разработана его математическая модель, которую следует использовать при проектировании энергосберегающих конструкций пневматических приводов рассматриваемого типа. Ее использование позволит облегчить выполнение задачи по получению заданных энергетических характеристик и производительности ударной машины, а также выбора нужных для этого рациональных значений конструктивных параметров привода при оптимальных затратах сжатого воздуха.

Ключевые слова: Ключевые слова: пневмопривод, поршень-ударник, фаза, начальный этап, математическая модель.

Stasiuk V.M.

Lutsk National Technical University

\section{MATHEMATICAL MODEL OF THE INITIAL STAGE OF THE FORMATION PHASE OF AN IMPACT OF THE PNEUMATIC DRIVE WITH A MECHANICAL CONNECTION BETWEEN THE PISTON-DRUMMER AND THE CONTROL SYSTEM}

Pneumatic drives are characterized by higher reliability compared to other types of drives during operation in adverse conditions. However, compressed air is a rather expensive energy source. Therefore, the task of cheapening the operation of pneumatic machines has become of particular urgency today. An effective solution to this task is a thorough analysis of drive cycles to identify the phases with the highest energy intensity and the search for constructive solutions to reduce it. 
The object of the study is a pneumatic drive of percussion machines with a mechanical connection between the piston-drummer and the control system. In this paper the phase of filling the chamber of the working stroke of such a drive is investigated as having a decisive influence on the formation of the power characteristics of a percussion machine and is directly related to the consumption of compressed air. The phase is considered to be divided into the initial and final stages, in which the formation of the driving momentum for the motion of the piston-drummer occurs.

A detailed analysis of the initial stage has been made, its mathematical model has been developed, which should be used in the design of energy-saving constructions of pneumatic drives of the type under consideration. Its use will facilitate the task of obtaining the specified energy characteristics and the speed of the percussion machine and selecting the optimal values of the design parameters of the drive at optimal compressed air consumption.

Keywords: pneumatic drive, piston-drummer, phase, initial stage, mathematical model. 